\title{
Spatial risk analysis for the introduction and circulation of six arboviruses in the Netherlands
}

Helen Joan Esser ${ }^{1,2,3^{*}+}$ (D) , Yorick Liefting ${ }^{1 \dagger}$, Adolfo Ibáñez-Justicia ${ }^{4}$, Henk van der Jeugd ${ }^{5}$, Chris A. M. van Turnhout ${ }^{6,7}$, Arjan Stroo ${ }^{4}$, Chantal B. E. M. Reusken ${ }^{3,8}$, Marion P. G. Koopmans ${ }^{8}$ and Willem Fred de Boer ${ }^{1}$

\begin{abstract}
Background: Arboviruses are a growing public health concern in Europe, with both endemic and exotic arboviruses expected to spread further into novel areas in the next decades. Predicting where future outbreaks will occur is a major challenge, particularly for regions where these arboviruses are not endemic. Spatial modelling of ecological risk factors for arbovirus circulation can help identify areas of potential emergence. Moreover, combining hazard maps of different arboviruses may facilitate a cost-efficient, targeted multiplex-surveillance strategy in areas where virus transmission is most likely. Here, we developed predictive hazard maps for the introduction and/or establishment of six arboviruses that were previously prioritized for the Netherlands: West Nile virus, Japanese encephalitis virus, Rift Valley fever virus, tick-borne encephalitis virus, louping-ill virus and Crimean-Congo haemorrhagic fever virus.
\end{abstract}

Methods: Our spatial model included ecological risk factors that were identified as relevant for these arboviruses by an earlier systematic review, including abiotic conditions, vector abundance, and host availability. We used geographic information system (GIS)-based tools and geostatistical analyses to model spatially continuous datasets on these risk factors to identify regions in the Netherlands with suitable ecological conditions for arbovirus introduction and establishment.

Results: The resulting hazard maps show that there is spatial clustering of areas with either a relatively low or relatively high environmental suitability for arbovirus circulation. Moreover, there was some overlap in high-hazard areas for virus introduction and/or establishment, particularly in the southern part of the country.

Conclusions: The similarities in environmental suitability for some of the arboviruses provide opportunities for targeted sampling of vectors and/or sentinel hosts in these potential hotspots of emergence, thereby increasing the efficient use of limited resources for surveillance.

Keywords: Risk mapping, Geographic Information System, West Nile virus, Japanese encephalitis virus, Rift Valley fever virus, Tick-borne encephalitis virus, Louping-ill virus, Crimean-Congo haemorrhagic fever virus, Vector-borne diseases

\footnotetext{
*Correspondence: helen.esser@outlook.com

${ }^{\dagger}$ Helen Joan Esser and Yorick Liefting contributed equally to this work

1 Wildlife Ecology \& Conservation Group, Wageningen University \& Research, Wageningen, The Netherlands

Full list of author information is available at the end of the article
}

\section{Background}

Arthropod-borne viruses, or arboviruses, are an increasing public health concern in Europe [1]. Diseases caused by endemic arboviruses such as West Nile virus (WNV), Crimean-Congo haemorrhagic fever virus (CCHFV), and tick-borne encephalitis virus (TBEV) are all increasing

c) The Author(s) 2020. This article is licensed under a Creative Commons Attribution 4.0 International License, which permits use, sharing, adaptation, distribution and reproduction in any medium or format, as long as you give appropriate credit to the original author(s) and the source, provide a link to the Creative Commons licence, and indicate if changes were made. The images or other third party material in this article are included in the article's Creative Commons licence, unless indicated otherwise in a credit line to the material. If material is not included in the article's Creative Commons licence and your intended use is not permitted by statutory regulation or exceeds the permitted use, you will need to obtain permission directly from the copyright holder. To view a copy of this licence, visit http://creativeco mmons.org/licenses/by/4.0/. The Creative Commons Public Domain Dedication waiver (http://creativecommons.org/publicdomain/ zero/1.0/) applies to the data made available in this article, unless otherwise stated in a credit line to the data. 
in incidence and distribution [2-4]. Moreover, the widespread occurrence and periodically high local abundance of competent vectors and reservoir hosts increase the probability that exotic arboviruses, such as Japanese encephalitis virus (JEV) or Rift Valley fever virus (RVFV), become established [5, 6]. Projected changes in land-use and climate, socio-economic development, and virus evolution may all contribute to larger and more frequent outbreaks in endemic regions, and promote geographic expansion of arboviruses, including those that were traditionally confined to tropical regions, into novel areas within Europe [7-10].

The above-mentioned mosquito-borne viruses (JEV, WNV and RVFV) and tick-borne viruses (CCHFV, TBEV and the closely related louping-ill virus LIV) have been marked as top priority arboviruses for the Netherlands based on epidemiological criteria, and their economic and societal impact [11]. Their potential emergence in the Netherlands may be facilitated by the country's unique combination of (i) high densities of livestock, which function as reservoir hosts for JEV, RVFV, CCHFV and LIV, (ii) great global connectivity in trade and travel through large airports and seaports, which increases the risk for arbovirus introduction, and (iii) priority policy to improve ecological conditions attracting wildlife (both resident and migratory) via habitat conservation and the establishment of wildlife corridors. Examples of these conservation initiatives are the National Ecological Network (NEN), the Natura 2000 network, and the Pan-European Ecological Network (PEEN), which are all aimed at higher wildlife mobility and larger distribution ranges, and hence may facilitate the spread of arboviruses with wildlife reservoirs. Moreover, increasingly warmer summers and milder winters improve the climatic suitability of the Netherlands for the establishment of arboviruses and their vectors [12, 13]. The recent outbreaks of Usutu virus in blackbirds and the first autochthonous human cases of TBE in this country, underline the continuous threat of arbovirus emergence $[14,15]$.

While history has shown that preventing the introduction and spread of arboviruses and their vectors into novel areas may be near impossible [16-19], potential outbreaks can be prevented or their effects mitigated by targeted early warning surveillance, preparedness planning, and control efforts (e.g. monitoring of vectors and/ or sentinel hosts, vaccination, education campaigns and biological control) in hazardous areas [20, 21]. However, predicting where arbovirus emergence is most likely to occur and hence, selecting locations where surveillance should be most effective, is a major challenge. A spatial analysis of ecological risk factors for arbovirus circulation can help identify such areas. Arboviruses are associated with the presence, abundance and interactions of specific vectors, reservoir hosts, and abiotic conditions that need to converge for arbovirus replication and transmission to occur [22]. Spatial modelling of these ecological risk factors can be used to map the environmental suitability ('hazard') for local circulation of arboviruses in regions beyond their current distribution [23-27].

In this study, we developed predictive hazard maps for the introduction and/or establishment of the six earlier prioritized arboviruses TBEV, LIV, CCHFV, JEV, WNV and RVFV in the Netherlands. Our spatial analysis included ecological risk factors that were identified as relevant for these arboviruses by an earlier systematic review, including abiotic conditions, vector abundance, and host availability [28]. We used geographic information system (GIS)-based tools and geostatistical analyses to model spatially continuous data on these risk factors to identify regions with suitable ecological conditions for endemic circulation. It is in these potential hotspots where surveillance efforts should be focused to enable early risk management. Our specific goal was to contribute to an integrated, multiplex surveillance strategy in which hazardous areas are monitored for the presence of multiple arboviruses simultaneously.

\section{Methods}

We considered Additional file 1: Table S1 from the systematic literature review by Esser et al. [22] to identify ecological risk factors associated with sustained circulation and spread of the six previously prioritized arboviruses (JEV, WNV, RVFV, CCHFV, TBEV and LIV). These factors included abiotic conditions (i.e. temperature, humidity and precipitation), vegetation cover, and the abundance of vectors and (reservoir) hosts such as migratory birds, livestock and deer. We then used nationwide continuous data on these ecological factors to construct hazard maps for the potential introduction and/or establishment of these arboviruses in the Netherlands. Factors that were not relevant for this country (e.g. elevation, presence of rice fields), or for which detailed information was not publicly available (e.g. point-to-point international livestock transport), were excluded from analysis. The available data allowed us to construct 9 hazard maps, 3 for the introduction of CCHFV, WNV, and JEV, and 6 for the establishment of each arbovirus (see below).

\section{Risk factors for introduction}

Long-distance dispersal of infected vectors and/or wildlife is an important mechanism for the introduction and spread of arboviruses into novel areas [28]. We considered the relative abundance of bird species that migrate from Africa and/or the Mediterranean area to the Netherlands in spring as principal risk factor for the introduction of WNV and CCHFV (see Additional file 1: Table S1, 
for a list of included bird species). As these birds have overwintering and/or stopover sites in endemic regions, they may potentially be viraemic with WNV or carry Hyalomma ticks infected with CCHFV upon arrival in the Netherlands [29, 30]. Indeed, even though there are no established populations of Hyalomma ticks in the Netherlands, immature ticks are incidentally imported by migratory birds [31, 32]. Migratory birds may also spread JEV via overlapping migratory flyways with birds migrating from JEV-endemic regions in southeast Asia [33]. We therefore included the relative abundance of these bird species as risk factor for the introduction of JEV (see Additional file 1: Table S2).

Long-distance dispersal of infected livestock is arguably the most important mechanism for the introduction of RVFV and LIV into novel areas [28, 34]. In addition, livestock imported from CCHFV-endemic regions may also carry infected Hyalomma ticks [35]. However, data on point-to-point international transport of livestock is commercially and socially sensitive and was therefore not made available by competent bodies for this study, which precluded the construction of introduction risk maps for RVFV and LIV. Host movement also plays an important role in the spread of TBEV throughout Europe [36, 37], but as this virus emerged in the Netherlands while this study was ongoing, we limited our analysis to estimating the establishment of TBEV.

\section{Risk factors for establishment}

For the mosquito-borne viruses, we included the following risk factors for establishment: (i) abundance of competent vectors; (ii) abundance of competent reservoir hosts; and (iii) suitable climatic conditions (Table 1). Competent mosquito species that have been prioritized as a veterinary and public health concern for the Netherlands, based on their local occurrence and vector status, include Aedes vexans for RVFV and Culex pipiens for WNV and RVFV [38-40]. More recently, European $C x$. pipiens mosquitoes were also shown to be competent vectors for JEV [5]. We estimated the abundance of these two mosquito species across the Netherlands using random forest models following the methods described in Ibañez-Justicia \& Cianci [41] and using the data reported in Ibañez-Justicia et al. [42]. Detailed information on these methods and the ecological variables used can be found in Additional file 2: Text S1.

Different reservoir hosts are involved in the transmission cycle of each of the three mosquito-borne viruses. Domestic ruminants are the most important reservoir host for RVFV [34]. We therefore included the abundance of cattle, sheep, and goats as risk factor for RVFV establishment. Pigs and horses do not play a significant role in RVFV epidemiology [43, 44], whereas the role of small mammals and ruminant wildlife, such as deer, in virus maintenance remains unclear $[45,46]$. These animals were therefore not included as risk factors for the establishment of RVFV. For JEV, Ardeid birds and pigs are the principal reservoir hosts [33]. Hence, we included the local abundance of Ardeid bird species that occur in the Netherlands (see Additional file 1: Table S3) and the abundance of pigs as risk factors for JEV establishment. West Nile virus is a multi-host pathogen that is maintained in a bird-mosquito transmission cycle [47]. Although the reservoir competence of many European bird species for WNV remains largely unknown, past outbreaks have often occurred near wetland areas, where large numbers of wetland birds and ornithophilic mosquitoes concentrate $[48,49]$. In addition, experimental studies have shown that the European carrion crow (Corvus corone), the jackdaw (Coloeus monedula), the magpie (Pica pica), the rock pigeon (Columba livia) and the house sparrow (Passer domesticus) are all highly susceptible to WNV infection and are competent reservoir hosts [50-54]. We therefore included the relative abundance of wetland bird species and that of crow, jackdaw, magpie, rock pigeon and house sparrow as risk factors for WNV establishment (see Additional file 1: Table S4).

Temperature, humidity, and precipitation have all been associated with outbreaks of the three mosquito-borne viruses that we consider here [22]. However, we included only temperature as abiotic risk factor because of its direct impact on vector competence, biting rates, and the extrinsic incubation period of the virus $[55,56]$. Other abiotic factors, such as precipitation or humidity, are indirectly related to virus circulation via their impact on mosquito abundance $[57,58]$, which we have modelled separately. Specifically, we included the average daily temperature during spring and summer (April to October) as risk factor for WNV and RVFV establishment, with higher temperatures corresponding with higher risk $[56,59]$. For JEV, we included the number of days when the average daily temperature was at least $25{ }^{\circ} \mathrm{C}$, a temperature limit above which JEV outbreaks occur [57].

For the tick-borne viruses, we included the following risk factors for establishment: (i) suitable tick habitat; (ii) presence of key host species for adult ticks and/or virus transmission; and (iii) abiotic conditions that facilitate virus transmission and/or tick development. Ticks are very sensitive to abiotic conditions and their survival is directly related to vegetation cover and leaf litter, which protects them from desiccation or freezing [60]. The principal vector of TBEV and LIV in Europe, Ixodes ricinus, occurs in a wide range of habitats, but it is typically found in woodlands and forests with thick undergrowth [61, 62]. Indeed, TBE incidence is positively correlated 


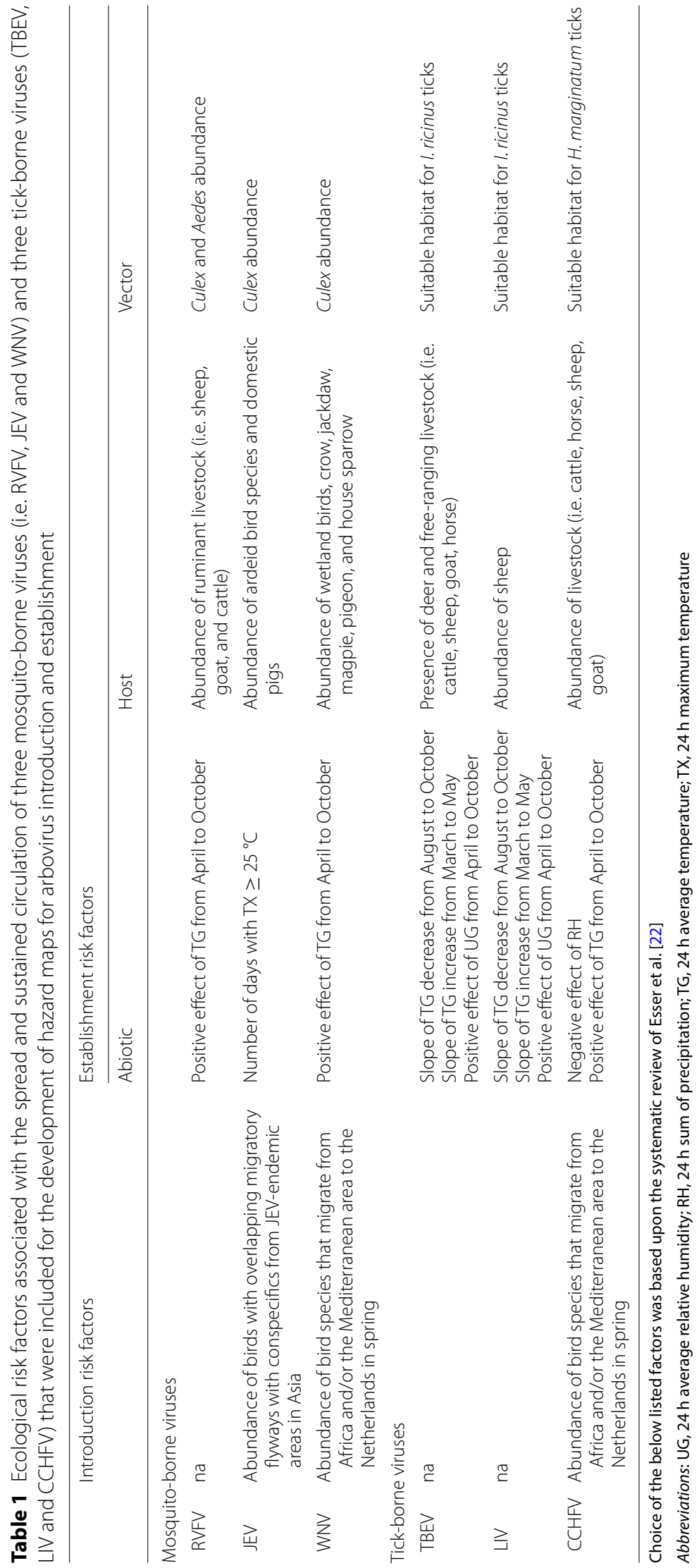


with the proportion of broad-leafed, mixed, and coniferous forest stands, which also provide habitat for small rodents that function as amplifying hosts for TBEV [6366]. In contrast, the most prominent European vector of CCHFV, Hyalomma marginatum, prefers open country habitat [62], with clinical cases of CCHF being positively correlated with the proportion of shrub or grassland cover and with habitat fragmentation in agricultural areas $[8,26,67]$. We therefore included different landuse types for I. ricinus and $H$. marginatum in our analysis and scored these on a scale of 1 to 3 , with higher values corresponding to more suitable habitat (see Additional file 1: Table S5).

Large herbivores are final hosts of adult I. ricinus and $H$. marginatum ticks, and are also directly involved as reservoir host in the transmission cycle of LIV and CCHFV $[35,36,68]$. In the Netherlands, deer presence rather than abundance best explains I. ricinus density [69]. In areas where deer and other wild herbivores are absent, free-ranging livestock that are used for nature management may instead maintain tick populations by feeding adult ticks [70]. We therefore used the presence of deer (i.e. roe deer Capreolus capreolus, fallow deer Dama dama, red deer Cervus elaphus) and free-ranging livestock (i.e. cattle, sheep, goat and horse) as a risk factor for high densities of I. ricinus and hence local circulation of TBEV. Louping ill virus most commonly occurs in upland habitats of the British Isles, where the red grouse (Lagopus lagopus scotica) is a competent transmission host, and the mountain hare (Lepus timidus) supports all three life stages of I. ricinus as well as non-viraemic transmission of LIV via co-feeding ticks [68]. Neither red grouse nor mountain hares are present in the Netherlands. Their absence, however, does not preclude local circulation of LIV in this country; sheep are highly competent reservoir hosts and are capable of maintaining an enzootic cycle with $I$. ricinus ticks, even in the absence of other key hosts such as deer [68]. We therefore included sheep abundance as a risk factor for the establishment of LIV. Livestock and hares are also principal host species for adult $H$. marginatum ticks and act as amplifying hosts for CCHFV [35]. Since the European hare (Lepus europaeus) is present throughout the Netherlands, but local abundance data were not available, we only included the abundance of livestock (i.e. cattle, goat, sheep and horse) as a risk factor for CCHFV establishment.

Rapid autumnal cooling followed by rapid spring warming are considered to be key climatic conditions for the transmission of TBEV and LIV as it enables synchronous activity of, and hence co-feeding transmission between, infected I. ricinus nymphs and uninfected larvae $[71,72]$. We therefore included the rate with which temperatures decreased in autumn and increased in spring as a risk factor for establishment of TBEV and LIV. Autumnal cooling was calculated as the slope of the average daily temperature decrease from August 1st to October 31st. Spring warming was calculated as the slope of the average daily temperature increase from March 1st to May 31st. As moist conditions are a controlling factor for the survival of I. ricinus, we also included a positive relationship with relative humidity [73]. In contrast, H. marginatum ticks are adapted to the warm climatic conditions of northern Africa and southern Europe [74]. Various modelling studies showed a northward shift in climate suitability of this species with increasing temperatures and decreasing rainfall as predicted under future climate change scenarios [75-77]. We therefore included a negative relationship with rainfall and a positive relationship with temperature during summer months (April to October) as risk factors for CCHFV establishment.

\section{Raw source data}

We used climatic data from the Royal Netherlands Meteorological Institute (KNMI). Daily meteorological data of 38 stations from 1 January 2010 until 31 December 2015 were used to interpolate (Spline function) daily maps with full coverage of the Netherlands. We followed the KNMI protocol for interpolating daily meteorological data [78]. We included the following factors: $24 \mathrm{~h}$ average temperature (TG; $0.1{ }^{\circ} \mathrm{C}$ ); $24 \mathrm{~h}$ maximum temperature (TX; $\left.0.1{ }^{\circ} \mathrm{C}\right), 24 \mathrm{~h}$ sum of precipitation (RH; $0.1 \mathrm{~mm}$ ); and $24 \mathrm{~h}$ average relative humidity (UG; \%). To identify suitable tick habitat, we used the LGN7 dataset [79] for landuse in the Netherlands, which differentiates between 39 land-use types (Additional file 1: Table S5). Livestock abundance data was obtained from the 2015 livestock survey database (Landbouwtelling 2015; poll date 1 April 2015) as provided by the Netherlands Enterprise Agency (RVO). Presence of free-ranging livestock in nature reserves was provided by Wageningen Environmental Research. Data on the presence of roe deer and hares was obtained from the Dutch National Database Flora and Fauna [80]. Data on the abundance of birds during the breeding season (spring) were obtained from the Bird Atlas of the Netherlands, based on nationwide fieldwork in 2013-2015 (www.vogelatlas.nl). The abundance of rare bird species was estimated per $5 \times 5 \mathrm{~km}$ grid square on a semi-quantitative ordinal scale (classes: $1-3 ; 4-10$; 11-25; 26-100; 101-500; 501-1000 breeding pairs). The abundance of common bird species was quantified by using geostatistical modelling, based on bird counts during standardized timed visits in eight systematically selected $1 \times 1 \mathrm{~km}$ grid squares per $5 \times 5 \mathrm{~km}$ square, and a set of environmental variables. For details of field work methods and modelling techniques, see Sovon Vogelonderzoek Nederland [81]. As the relative importance of 
each bird species for virus transmission remains unclear, we weighted each bird species equally in our analyses. For rare bird species, we took the geometric mean per abundance class, and then normalized the abundance of each species between 0 and 100. For common bird species, we directly normalized the abundance data by assigning 100 to cells where the species was most common and 0 where it was absent.

\section{Construction of hazard maps}

We used 'static risk mapping' (sensu [82]) to characterize the spatial variation in the above-described ecological risk factors for arbovirus circulation. First, we generated a grid of $5 \times 5 \mathrm{~km}$ covering the Netherlands in ESRI ArcGIS 10.5 (ESRI 2017). Cells that had their centroids $>1 \mathrm{~km}$ away from land were excluded from the analyses to prevent edge effects. Each ecological risk factor was represented by a single GIS-layer that covered the entire grid. Values for each layer were averaged per cell and then normalized $(0-100)$ over the entire grid to allow adding or subtracting in further analyses (see below). All individual layers are provided in Additional file 3: Figures S1-S19.

The introduction maps for CCHFV, WNV and JEV consisted of one GIS-layer each, i.e. the relative abundance of migratory birds (Table 1 ). In contrast, the establishment maps of the six arboviruses were constructed by combining (overlaying) multiple GIS-layers. For this, we first classified each of these layers (risk factors) as belonging to either abiotic conditions, vector abundance, or host availability (Table 1). Because the relative importance of each risk factor varies between endemic regions [22], it remains unclear which factor(s) will contribute most to virus circulation in the Netherlands. All layers (risk factors) within each of the groups (abiotic, vector and host) were therefore weighted equally in the analysis by averaging all values per grid cell. The three groups were then overlaid and weighted equally again to prevent bias towards one particular group for arbovirus establishment.

For example, in the case of CCHFV, the host layer consisted of livestock abundance, the vector layer consisted of suitable habitat for $H$. marginatum, whereas the abiotic layer was a combination of temperature and precipitation (Table 1). As we included a positive effect of temperature but a negative effect of precipitation, their values could not simply be averaged. We therefore subtracted the precipitation values from 100 to obtain a scale where higher values correspond with lower precipitation (which is favourable for $H$. marginatum). Temperature and precipitation values were then averaged per grid cell and normalized. The three abiotic, host, and vector layers were then averaged and normalized again to construct the establishment map (see Additional file 4: Figures S20-S25, for a schematic representation of the procedure).

The hazard maps illustrate spatial differences in optimal environmental conditions for virus circulation and therefore portray relative hazard rather than actual hazard. This relative hazard is expressed on a scale between 0 (low hazard) and 100 (high hazard) and is visualised on the maps with colours ranging from black (low hazard area) to red (high hazard area). Because TBEV emerged in the Netherlands while this study was ongoing, we compared our establishment map with locations where TBEV was detected in ticks, wildlife, and humans, and where serologically positive roe deer were found [83]. These data were obtained from the website of the National Institute for Public Health and the Environment (RIVM), to which the Dutch Wildlife Health Centre, ErasmusMC, LabMicTa, MPH Services (GGD), Wageningen University and Research, and Artemis One Health contributed. In addition, we compared our WNV establishment map with locations where serologically positive birds were recently reported [84].

\section{Results}

The introduction maps highlight locations with large concentrations of migratory birds from appropriate source areas or species groups, which may either be infected with WNV or JEV, or carry CCHFV-infected $H$. marginatum ticks from endemic regions (Figs. 1, 2 and 3). The establishment maps indicated that for WNV, the southern and western part of the Netherlands are most suitable for endemic circulation (Fig. 4), while for JEV suitability was highest in the southern and eastern part of the country (Fig. 5). For RVFV and CCHFV, only few locations were classified as having a relatively high hazard for establishment, but they were all located in the south (Figs. 6, 7). Establishment hazard of TBEV was highest in nature areas in central, southern, and eastern parts of the country, where the combination of seasonal temperature profiles, suitable tick habitat and host availability are most likely to allow for co-feeding transmission between infected and uninfected ticks on rodent hosts (Fig. 8). In contrast, the hazard of LIV establishment was highest in the north of the country (Fig. 9). Overlaying all of the establishment maps showed that overall hazard of endemic arbovirus circulation was highest in the southern parts of the country; a region characterized by a warmer climate, which positively affects vectorial capacity and vector abundance [56, 75, 85] (Fig. 10).

As TBEV recently emerged in the Netherlands, we compared our establishment maps with the specific locations where the virus has been detected in ticks, humans, 
and wildlife and where seropositive roe deer were found [83]. Locations where PCR-positive ticks, wildlife and human cases have been found are all marked as highhazard areas, while serological evidence is present in medium- to high-hazard areas, providing supportive evidence for the validity of our maps (Fig. 8). In addition, WNV-specific neutralizing antibodies were recently detected in birds (Eurasian coot Fulica atra and carrion crow) from Amsterdam, Rotterdam and The Hague [84]. While it is possible that these birds acquired WNV outside of the Netherlands, the cities in which they were found are located in the western part of the country, where the relative hazard for establishment was highest (Fig. 4).

\section{Discussion}

We performed a spatial analysis of ecological risk factors for circulation of six arboviruses (WNV, JEV, RVFV, CCHFV, TBEV and LIV) to identify areas in the Netherlands with the highest potential for their introduction and subsequent establishment. We created introduction maps for WNV, JEV and CCHFV, and establishment maps for each of the six arboviruses (Figs. 1, 2, 3, 4, 5, 6, 7,8 and 9). We stress that these maps portray spatial variation in relative hazard, i.e. arbovirus circulation is more likely in certain locations than in others, rather than actual hazard. That being said, the similarity between the predicted high-hazard areas and the locations where actual TBEV-cases and WNV-serologically positive birds were reported, provides some confidence that our spatial model, despite its relative simplicity, can be used to identify regions in the Netherlands where arbovirus emergence is most likely.

While TBEV appears to be locally established in the Netherlands, autochthonous WNV infections in mosquitoes or animals have yet to be reported, despite widespread availability of competent vectors [39] and expected introduction by viraemic birds [30, 86]. Temperature is regarded as the key limiting factor for WNV transmission in northern Europe [56, 87], but the virus is predicted to spread into this region via migratory birds under future climate change scenarios [88]. Similar predictions have been made for $H$. marginatum, which is both the main vector and reservoir host of CCHFV in Europe [75]. A population model showed that selfsustaining populations of this tick species were absent in areas where yearly accumulated temperatures drop below $3000-4000{ }^{\circ} \mathrm{C}[60]$. In the Netherlands, the yearly accumulated temperature averaged $3751{ }^{\circ} \mathrm{C}$ during our study period (2010-2015), but is expected to rise above $4000{ }^{\circ} \mathrm{C}$ under the predicted temperature increase of $1{ }^{\circ} \mathrm{C}$ by 2030 [13]. However, this temperature limit was already exceeded in the exceptionally warm year of 2018 , and the first imported Hyalomma ticks have already been found on migratory birds, horses and humans [31, 32]. Together, these findings warrant increased surveillance for TBEV, WNV and CCHFV.

In contrast, the potential introduction of RVFV, JEV and LIV is probably more dependent on human activities, such as trade and travel, rather than natural movement of hosts and/or vectors. For example, the red grouse plays an important role in the transmission cycle of LIV in the UK [89], but this species is absent in the Netherlands. Its closest relative, the black grouse Lyrurus tetrix, is critically endangered and has only a small population on the Sallandse Heuvelrug. Past introductions of LIV into other parts of Europe were likely due to international transport of infected sheep [90], and this is also the most plausible route of introduction for the Netherlands. Subsequent establishment of LIV is possible through a competent and abundant vector, I. ricinus [68]. Likewise, few bird species that arrive in the Netherlands in summer have overlapping migratory flyways with birds from JEV-endemic areas in Asia, resulting in limited potential for introduction when temperatures are suitable for viral replication. Such a long-distance migration might also reduce the viremia of these birds, so that they are no longer infectious upon arrival [91]. Alternatively, introduction of JEV as well as RVFV via infected mosquitoes that come with trade or air traffic is theoretically possible [91], but is considered to be less likely for the Netherlands than entry through (illegal) trade of birds (JEV) and livestock (RVFV) [92]. Access to animal trade data is of critical importance for mapping this hazard, and it is therefore extremely unfortunate that this information was not made available by the relevant bodies, who deemed it to be economically too sensitive.

The use of GIS-based models has become increasingly common in the field of spatial epidemiology to map the potential emergence of diseases in areas beyond their current distribution [82, 93-96]. Our approach is similar and generated useful results that are corroborated with recent findings of e.g. TBEV emergence. Further, overlap between some of the arboviruses' high-hazard areas supports the implementation of integrated surveillance in regions where multiple arboviruses may emerge. On the other hand, it is difficult to weigh for differences in importance or effect sizes of different risk factors in our analyses at this stage. More experimental research is required to disentangle the effects of the different, often confounded environmental factors and to estimate their relative contribution to virus circulation. However, it is relatively easy to include a weighting factor in our analyses, or to add additional layers (e.g. risk for human exposure via recreation) so that the accuracy of the predictions can be improved. These predictions also need to 


\section{$\AA$}

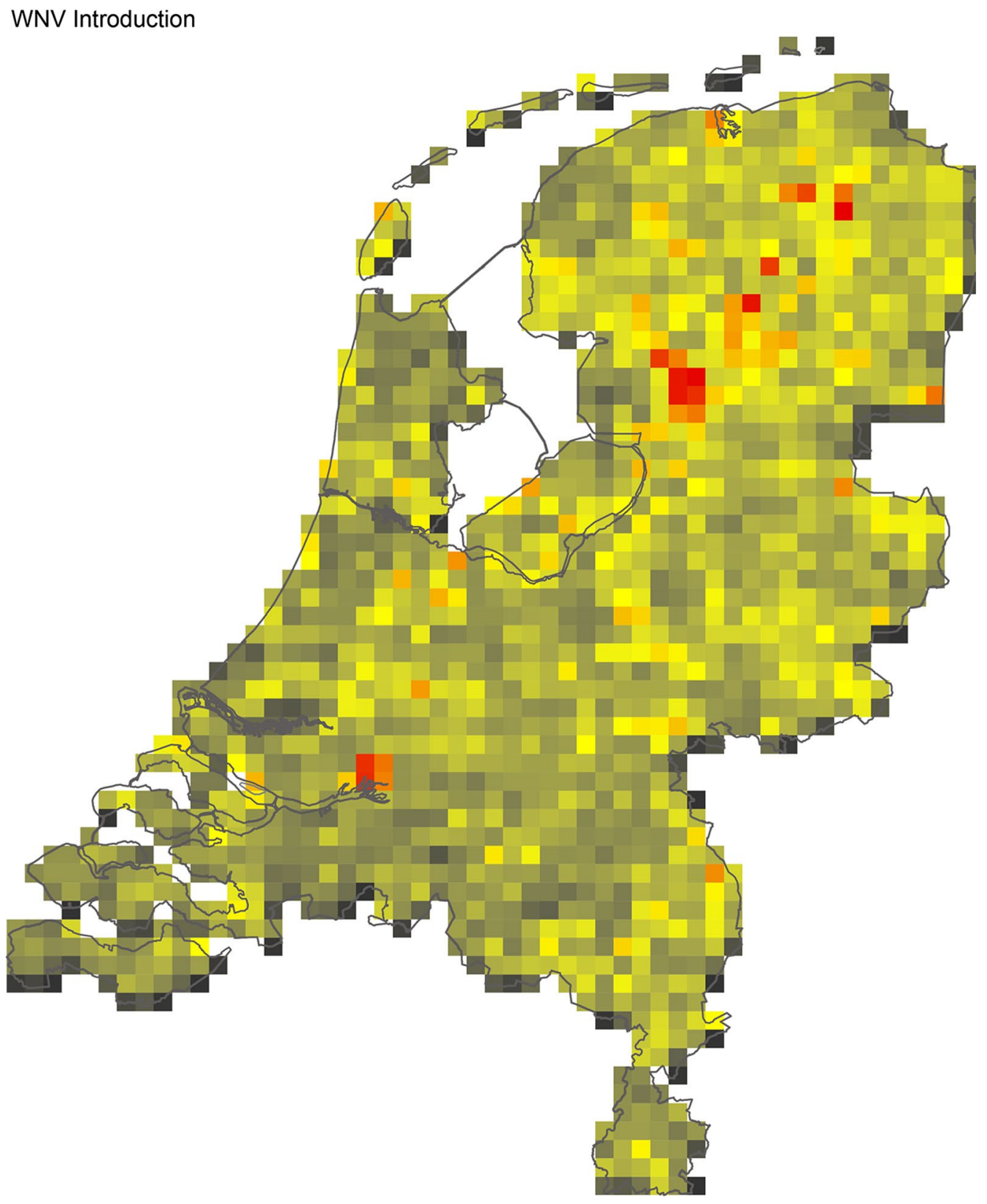

Standardized values, linear scale

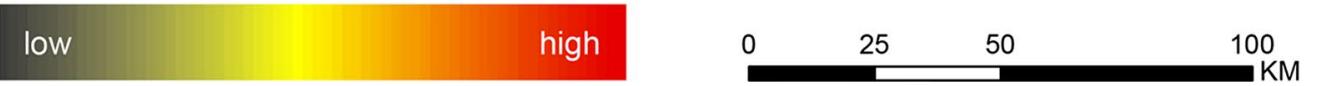

Fig. 1 Hazard map for the introduction of West Nile virus (WNV) in the Netherlands

be tested, and such a validation phase is a fundamental requirement to improve our understanding of the underlying causal mechanisms driving these spatial patterns.
Testing the accuracy of these predictions will be a challenge, as most of the arboviruses considered here are still presumed absent from the Netherlands (i.e. CCHF, LIV, 


\section{N}

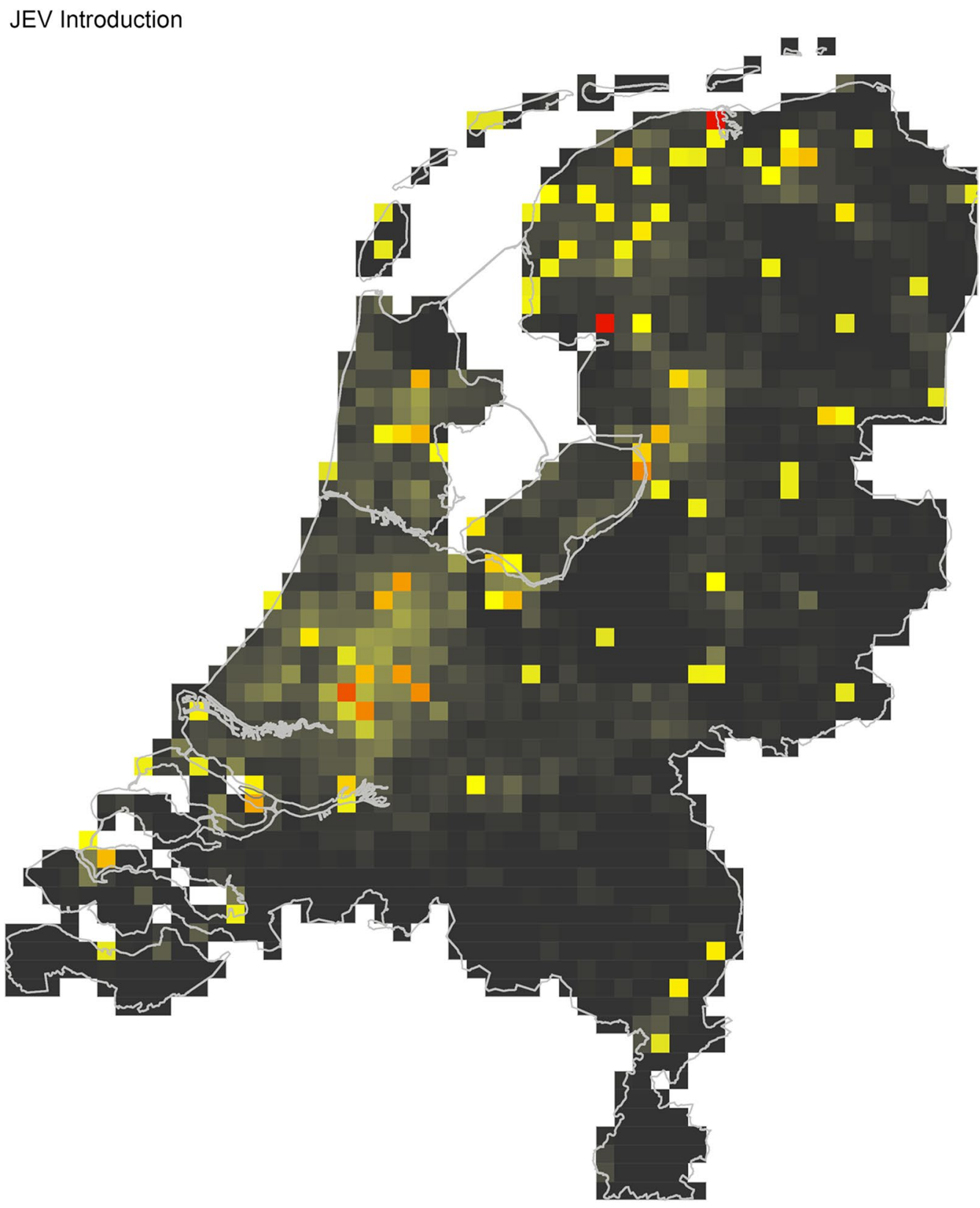

Standardized values, linear scale

$\begin{array}{llllll}\text { low high } & 0 & 25 & 50 & 100 \\ \text { KM }\end{array}$

Fig. 2 Hazard map for the introduction of Japanese encephalitis virus (JEV) in the Netherlands

JEV, WNV and RVFV). However, the recent emergence of TBEV and the closely to WNV-related Usutu virus [15], might offer some prospect for testing these predictions. Indeed, the establishment pattern of USUV in the
Netherlands shows some resemblance to the establishment map for WNV, with a gradual northwest-oriented spread from the southeast of the Netherlands [15]. 


\section{$\stackrel{\Lambda}{\Lambda}$}

\section{CCHFV Introduction}

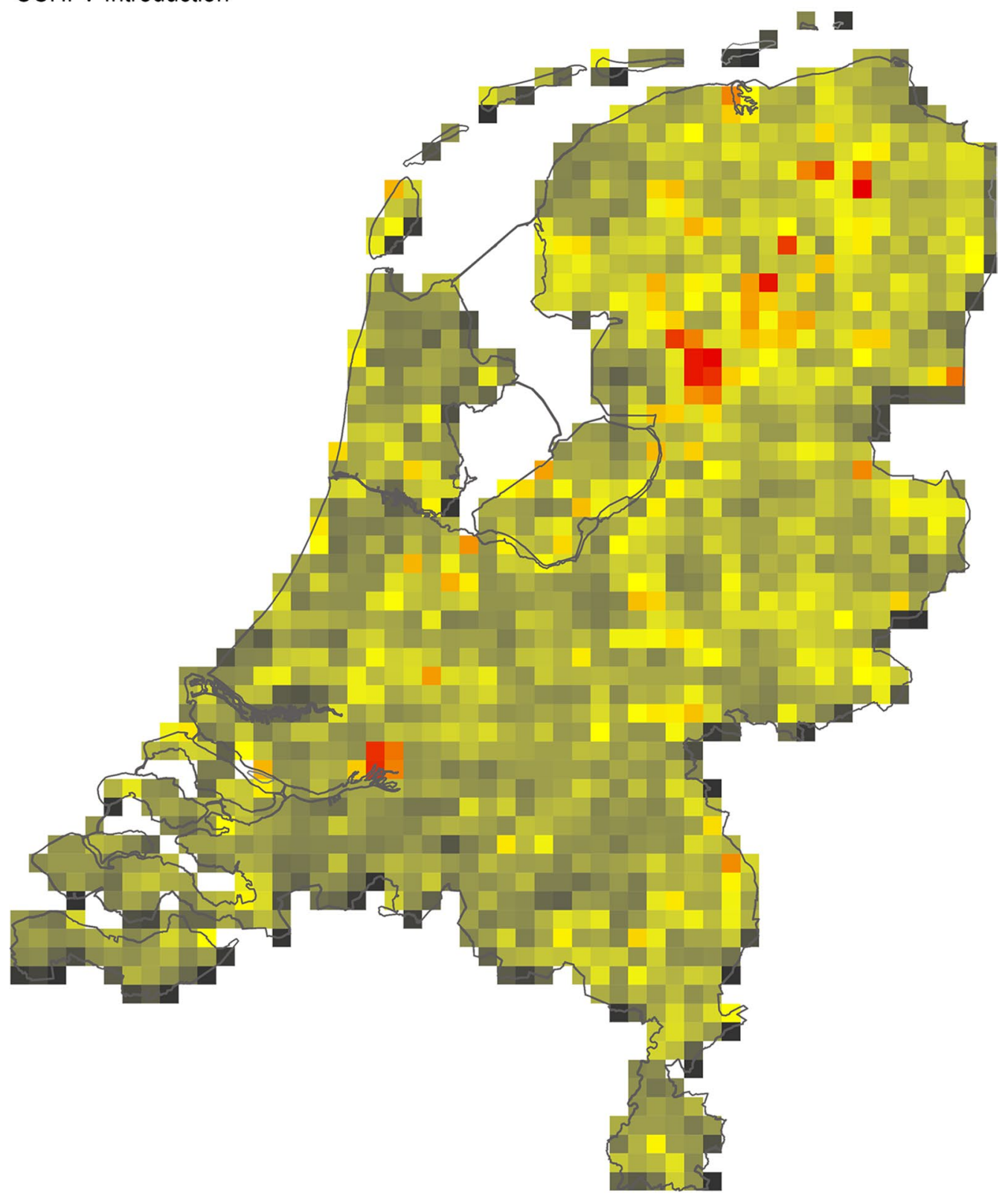

Standardized values, linear scale

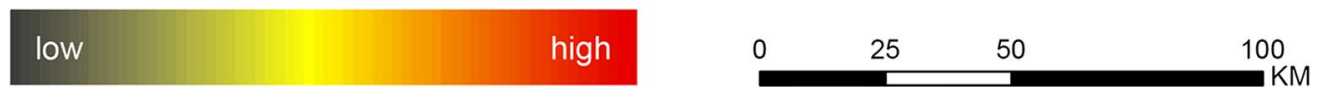

Fig. 3 Hazard map for the introduction of Crimean-Congo haemorrhagic fever virus (CCHFV) in the Netherlands 


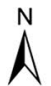

\section{WNV Establishment}

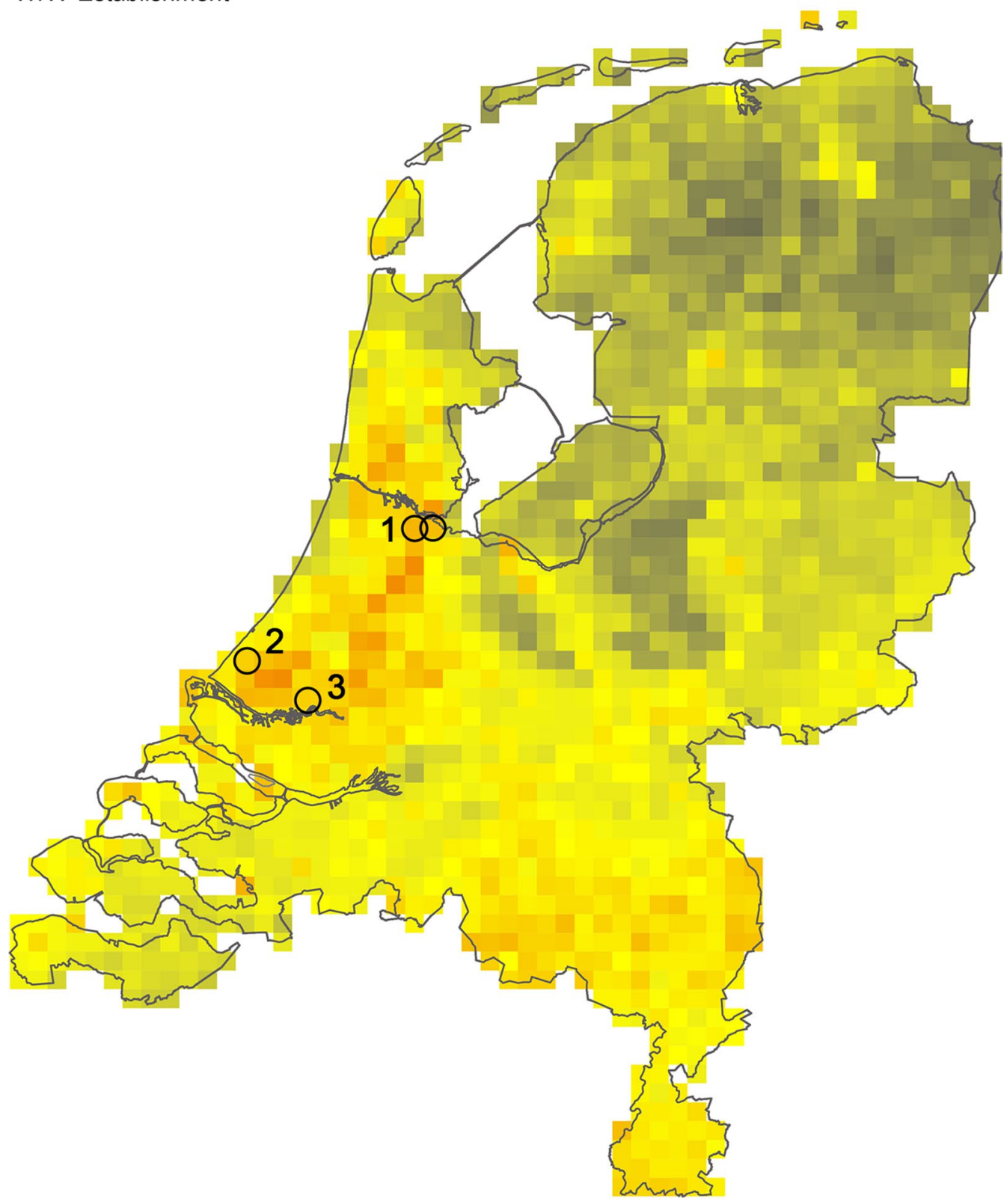

Standardized values, linear scale

$$
\text { low } \quad \text { high } \quad \begin{array}{llll}
0 & 25 & 50 & 100
\end{array}
$$

Fig. 4 Hazard map for the establishment of West Nile virus (WNV) in the Netherlands. Locations where birds with WNV-neutralizing antibodies were caught [83] are indicated with black circles. Location 1: Amsterdam; Location 2: The Hague; Location 3: Rotterdam 


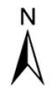

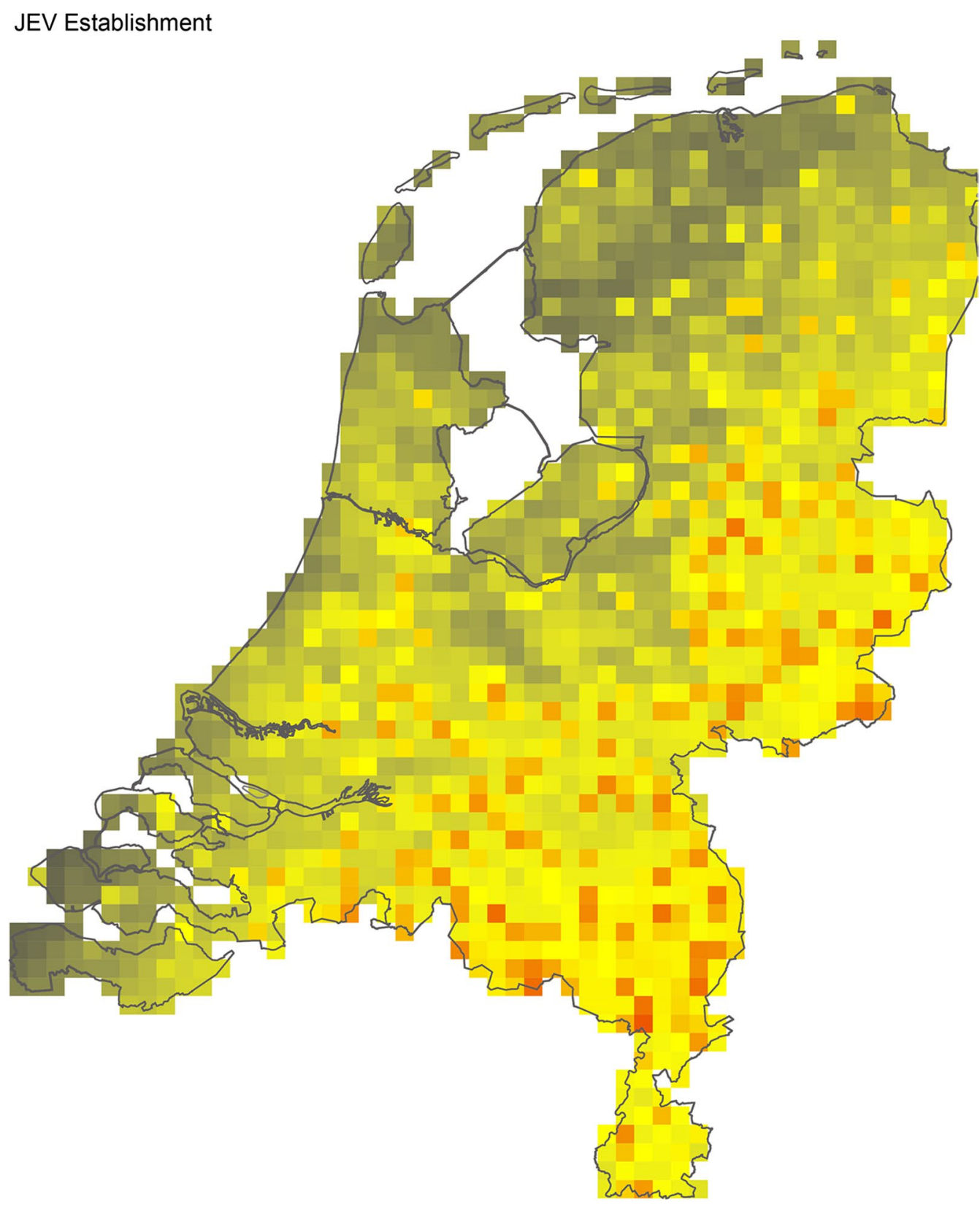

Standardized values, linear scale

Fig. 5 Hazard map for the establishment of Japanese encephalitis virus (JEV) in the Netherlands 


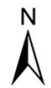

\section{RVFV Establishment}

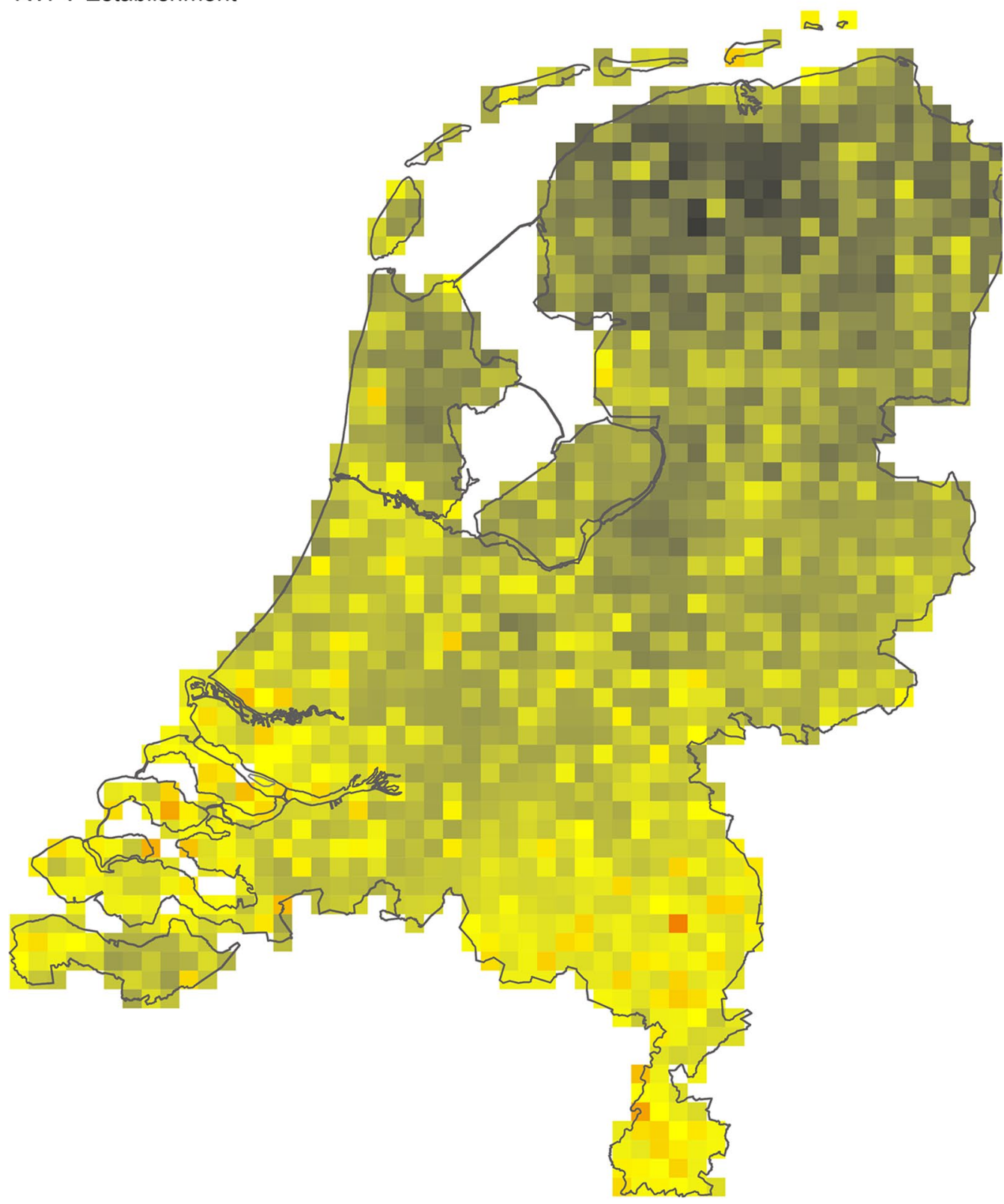

Standardized values, linear scale

low high $\quad \begin{array}{llll}0 & 25 & 50 & 100 \\ \text { KM }\end{array}$

Fig. 6 Hazard map for the establishment of Rift Valley fever virus (RVFV) in the Netherlands 


\section{^}

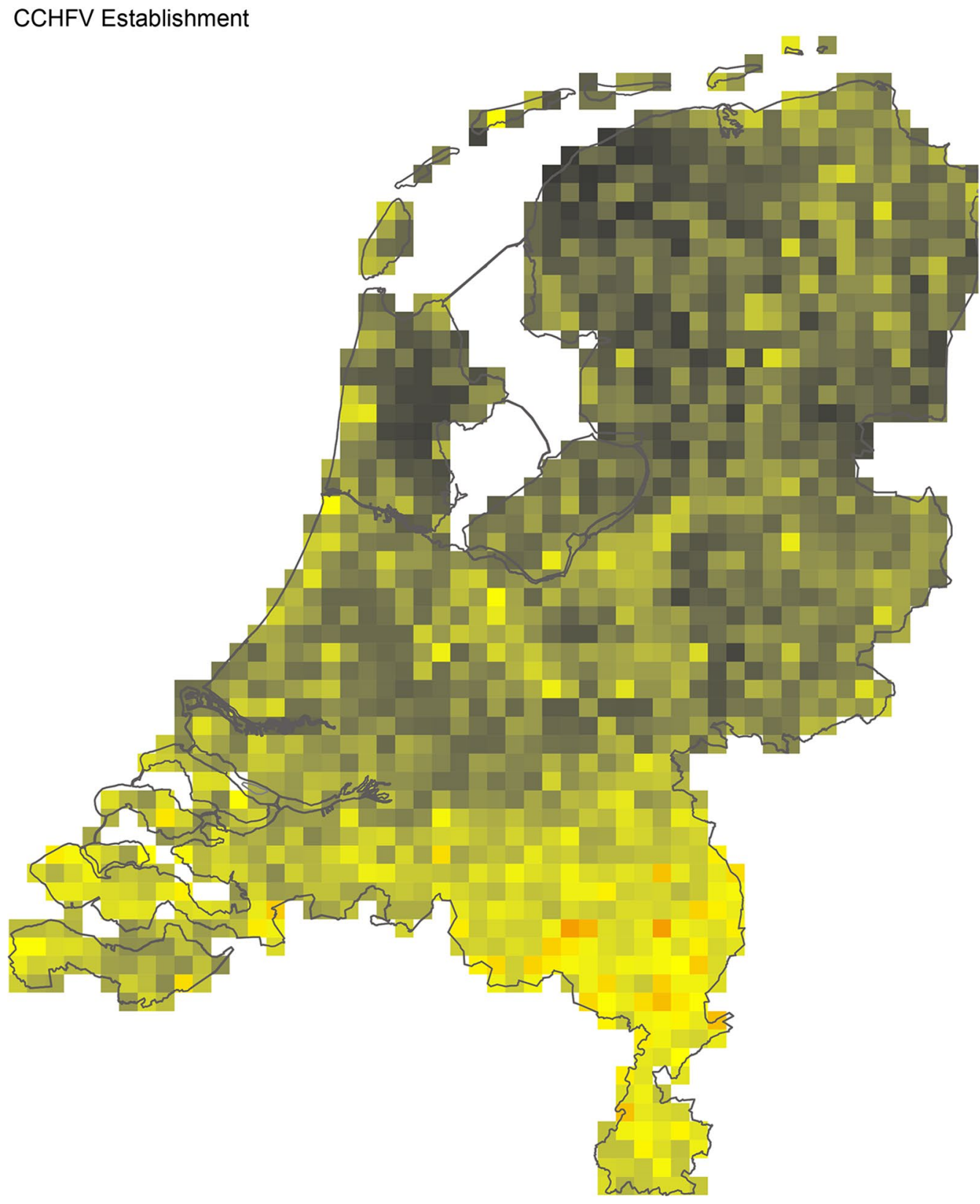

Standardized values, linear scale

low high $\quad \begin{array}{llll}0 & 25 & 50 & 100 \\ \mathrm{KM}\end{array}$

Fig. 7 Hazard map for the establishment of Crimean-Congo haemorrhagic fever virus (CCHFV) in the Netherlands

\section{Conclusions}

The use of spatial models has become a key method to map the environmental suitability for arbovirus circulation and to target surveillance in regions of potential emergence. Our analyses and the generated hazard maps show that there is spatial clustering of areas with either a relatively low or high potential for arbovirus introduction and/or establishment in the Netherlands. Importantly, 


\section{^}

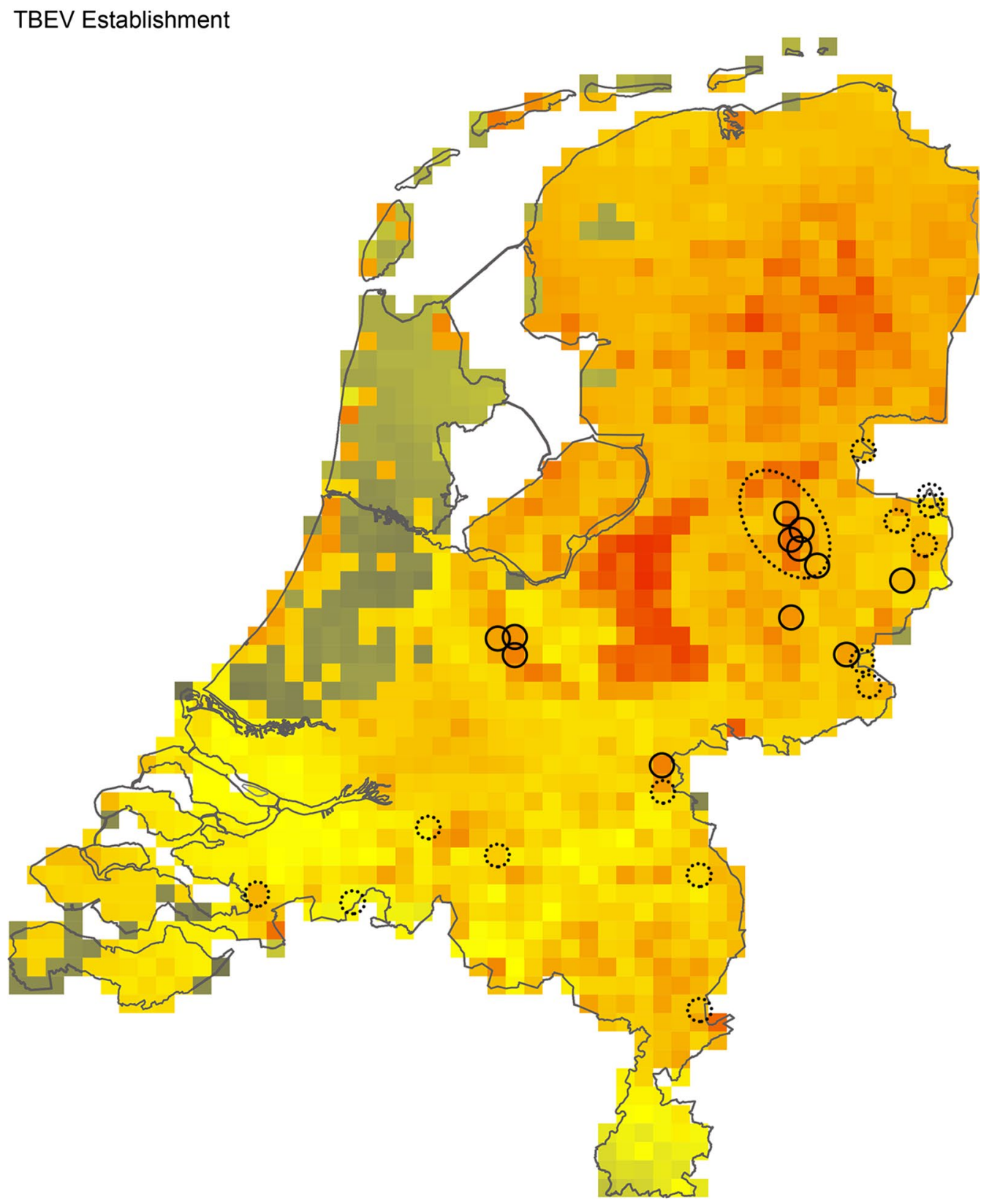

Standardized values, linear scale

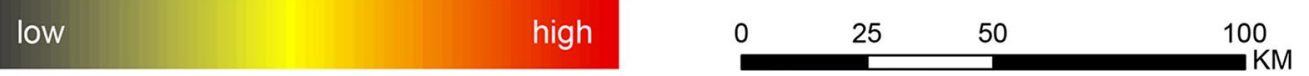

Fig. 8 Hazard map for the establishment of tick-borne encephalitis virus (TBEV) in the Netherlands. Locations where TBEV-positive ticks, wildlife, and human cases were found are indicated with black circles. Locations where TBEV-seropositive wildlife were found are indicated with dashed circles [83] 


\section{$\stackrel{N}{\Lambda}$}

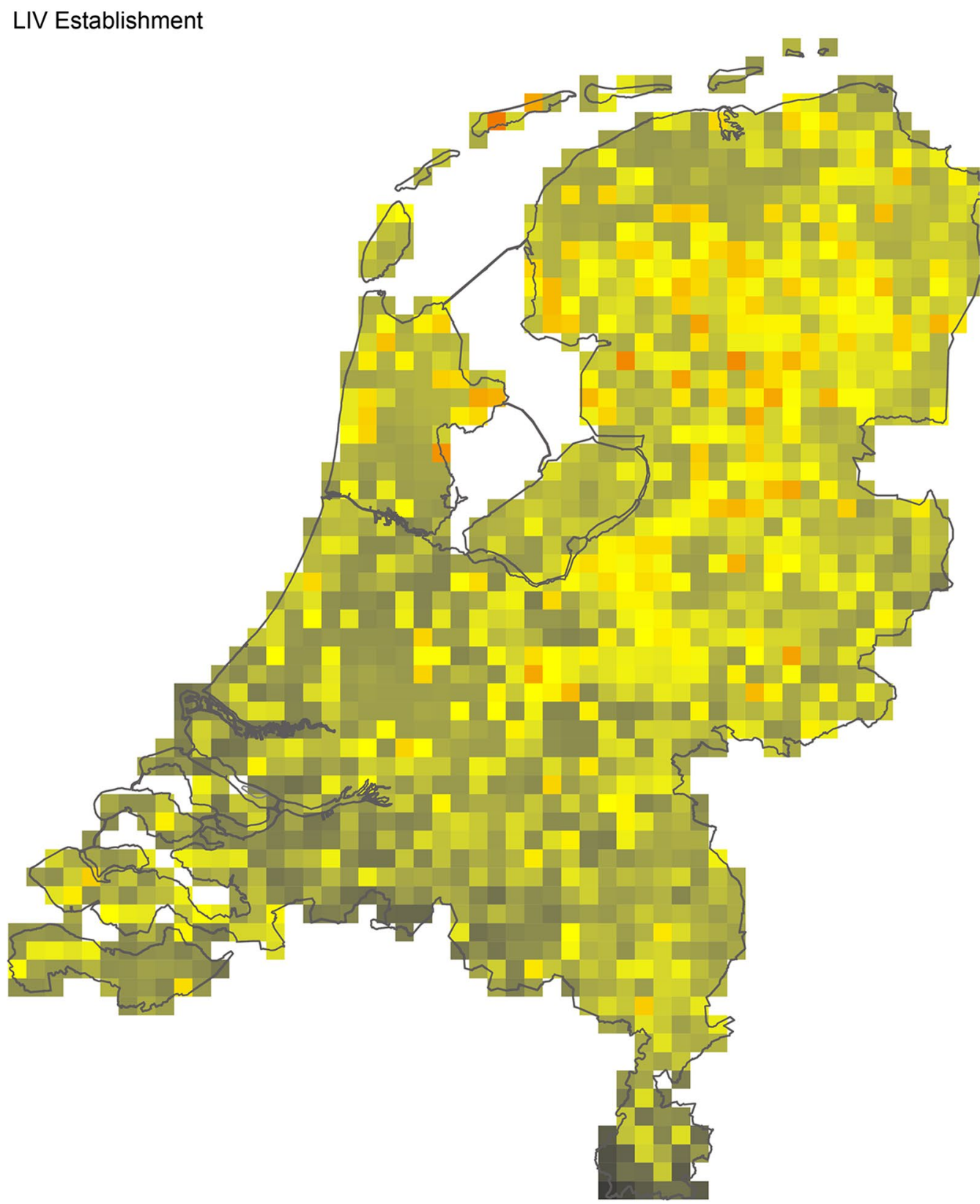

Standardized values, linear scale

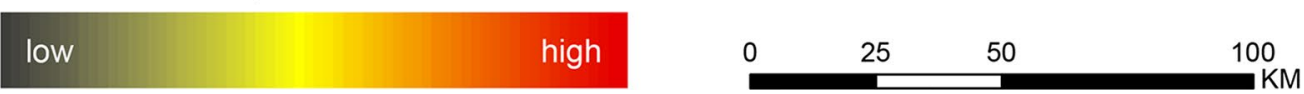

Fig. 9 Hazard map for the establishment of louping-ill virus (LIV) in the Netherlands 


\section{$\stackrel{\Lambda}{\Lambda}$}

\section{Combined Establishment}

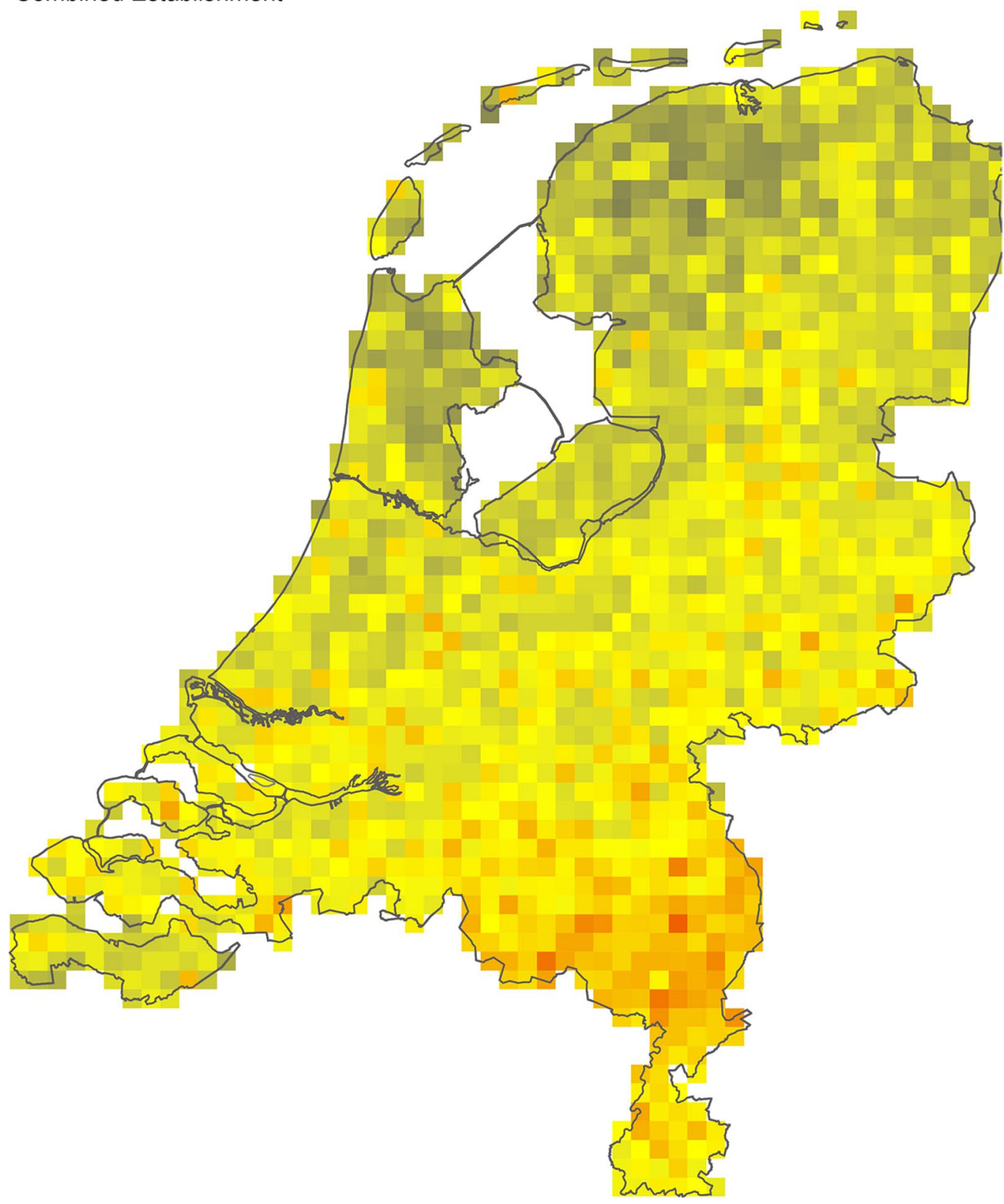

Standardized values, linear scale

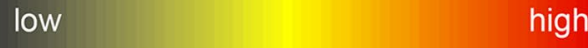

Fig. 10 Combined establishment map for all six arboviruses (WNV, JEV, RVFV, TBEV, CCHFV and LIV) shows that the relative hazard is highest in the southern part of the Netherlands 
some of these high-hazard areas overlap. Our combined map, showing the summed hazard for all six arboviruses per cell, shows that overall hazard is highest in the southern part of the country. Sampling of vectors and sentinel hosts should be focused in these key priority areas, where several arboviruses may emerge. Such targeted sampling increases the efficient use of limited resources for surveillance. Thus, the construction and subsequent overlaying of multiple hazard maps provides a promising approach for an integrated, cost-efficient, multiplex-surveillance strategy that targets multiple arboviruses simultaneously.

\section{Supplementary information}

Supplementary information accompanies this paper at https://doi. org/10.1186/s13071-020-04339-0.

Additional file 1: Table S1. Bird species that migrate from Africa and/or the Mediterranean area to North-western Europe during spring. Table S2. Bird species that have overlapping migratory flyways with conspecifics migrating from JEV-endemic regions in southeast Asia. Table S3. Ardeid bird species of the Netherlands. Table S4. Wetland bird species of the Netherlands. Table S5. Land cover classes of the Netherlands (LGN7) that were included as habitat for Ixodes ricinus and Hyalomma marginatum ticks. Habitat suitability ranged from 0 (not suitable) to 3 (very suitable).

Additional file 2: Text S1. Description of the methods used for modelling mosquito abundance, including information on mosquito data collection, the environmental data used and the statistical methods applied.

Additional file 3: Figures S1-S19. Individual layers (ecological risk factors) that were used for constructing the hazard maps.

Additional file 4: Figures S20-S25. Schematic representation of the steps taken to construct the hazard maps for the establishment of each of the six arboviruses.

\section{Abbreviations}

CCHFV: Crimean-Congo haemorrhagic fever virus; JEV: Japanese encephalitis virus; LIV: Louping-ill virus; RVFV: Rift Valley fever virus; TBEV: Tick-borne encephalitis virus; WNV: West Nile virus; KNMI: Royal Netherlands Meteorological Institute; $\mathrm{RH}$ : 24-h sum of precipitation; TG: 24 -h average temperature; TX: 24-h maximum temperature; UG: 24-h average relative humidity.

\section{Acknowledgements}

We thank the following organisations and institutes for providing raw source data: Royal Netherlands Meteorological Institute (KNMI), Netherlands Enterprise Agency (RVO), Wageningen Environmental Research, Dutch National Database Flora and Fauna; and the Dutch Centre for Field Ornithology (SOVON).

\section{Authors' contributions}

WFB, CBEMR and MPGK conceived the study. HJE identified the ecological risk factors and YL obtained the associated raw source data. AIJ, HJ, CAMT and AS provided input data. YL performed the analyses and created the hazard maps. HJE, CBEMR and WFB wrote the manuscript with input from all authors. All authors read and approved the final manuscript.

\section{Funding}

This study was financially support by a ZonMw grant (522001004).

\section{Availability of data and materials}

The abiotic data that support the findings of this study are available from the Royal Netherlands Meteorological Institute (KNMI). However, restrictions apply to the availability of the host and vector data (e.g. abundance of livestock and birds, land-use dataset), which were used under license for the current study, and so are not publicly available. Data are however available from the authors upon reasonable request and with permission of the parties from which these data were obtained.

\section{Ethics approval and consent to participate}

Not applicable.

\section{Consent for publication}

Not applicable.

\section{Competing interests}

The authors declare that they have no competing interests.

\section{Author details}

${ }^{1}$ Wildlife Ecology \& Conservation Group, Wageningen University \& Research, Wageningen, The Netherlands. ${ }^{2}$ Laboratory of Entomology, Wageningen University \& Research, Wageningen, The Netherlands. ${ }^{3}$ Centre for Infectious Disease Control, National Institute for Public Health and the Environment, Bilthoven, The Netherlands. ${ }^{4}$ Centre for Monitoring of Vectors (CMV), National Reference Centre (NRC), Netherlands Food and Consumer Product Safety Authority (NVWA), Ministry of Agriculture, Nature and Food Quality, Wageningen, The Netherlands. ${ }^{5}$ Vogeltrekstation - Dutch Centre for Avian Migration and Demography (NIOO-KNAW), Wageningen, The Netherlands. ${ }^{6}$ Sovon Dutch Centre for Field Ornithology, Nijmegen, The Netherlands. ${ }^{7}$ Department of Animal Ecology \& Ecophysiology, Institute for Water and Wetland Research, Radboud University, Nijmegen, The Netherlands. ${ }^{8}$ Department of Viroscience, WHO CC for Arbovirus and Viral Hemorrhagic Fever Reference and Research, Erasmus University Medical Centre, Rotterdam, The Netherlands.

Received: 13 April 2020 Accepted: 1 September 2020

Published online: 10 September 2020

\section{References}

1. Sigfrid L, Reusken C, Eckerle I, Nussenblatt V, Lipworth S, Messina J, et al. Preparing clinicians for (re-)emerging arbovirus infectious diseases in Europe. Clin Microbiol Infect. 2017;24:229-39.

2. Süss J. Tick-borne encephalitis 2010: epidemiology, risk areas, and virus strains in Europe and Asia—an overview. Ticks Tick Borne Dis. 2011:2:2-15.

3. Papa A. Emerging arboviral human diseases in southern Europe. J Med Virol. 2017:89:1315-22.

4. Holding M, Dowall S, Medlock J, Carter D, Pullan S, Lewis J, et al. Tickborne encephalitis virus, United Kingdom. Emerg Infect Dis. 2020;26:90-6.

5. de Wispelaere M, Desprès P, Choumet V. European Aedes albopictus and Culexpipiens are competent vectors for Japanese encephalitis virus. PLoS Negl Trop Dis. 2017;11:e0005294.

6. Rolin Al, Berrang-Ford L, Kulkarni MA. The risk of Rift Valley fever virus introduction and establishment in the United States and European Union. Emerg Microbes Infect. 2013;2:e81.

7. Šumilo D, Bormane A, Asokliene L, Vasilenko V, Golovljova I, Avsic-Zupanc $\mathrm{T}$, et al. Socio-economic factors in the differential upsurge of tick-borne encephalitis in central and eastern Europe. Rev Med Virol. 2008;18:81-95.

8. Estrada-Peña A, Vatansever Z, Gargili A, Ergönul Ö. The trend towards habitat fragmentation is the key factor driving the spread of CrimeanCongo haemorrhagic fever. Epidemiol Infect. 2010;138:1194-203.

9. Webster JL, Stapleford KA. Arbovirus adaptation: roles in transmission and emergence. Curr Clin Microbiol Rep. 2017;4:159-66.

10. Vogels CB, Hartemink N, Koenraadt CJ. Modelling West Nile virus transmission risk in Europe: effect of temperature and mosquito biotypes on the basic reproduction number. Sci Rep. 2017;7:5022.

11. Havelaar AH, Van Rosse F, Bucura C, Toetenel MA, Haagsma JA, Kurowicka $D$, et al. Prioritizing emerging zoonoses in the Netherlands. PLOS ONE. 2010:5:e13965.

12. Gould EA, Higgs S. Impact of climate change and other factors on emerging arbovirus diseases. Trans R Soc Trop Med Hyg. 2009;103:109-21.

13. van den Hurk B, Siegmund P, Klein Tank A. KNMI'14: climate change scenarios for the 21st century - a Netherlands perspective. Scientific Report WR2014-01. De Bilt, the Netherlands: KNMl; 2014. www.climatescenario s.n. 
14. Dekker M, Laverman GD, de Vries A, Reimerink J, Geeraedts F. Emergence of tick-borne encephalitis (TBE) in the Netherlands. Ticks Tick Borne Dis. 2019;10:176-9.

15. Rijks JM, Kik ML, Slaterus R, Foppen RPB, Stroo A, IJzer J, et al. Widespread Usutu virus outbreak in birds in the Netherlands 2016. Euro Surveill. 2016;21:30391.

16. Zannoli S, Morotti M, Denicolò A, Tassinari M, Chiesa C, Pierro A, et al. Chikungunya virus and Zika virus in Europe. In: Higgs S, Vanlandingham DL, Powers A, editors. Chikungunya and zika viruses: global emerging health threats. London: Elsevier; 2018. p. 193-214.

17. Cadar D, Lühken R, van der Jeugd H, Garigliany M, Ziegler U, Keller M, et al. Widespread activity of multiple lineages of Usutu virus, western Europe, 2016. Euro Surveill. 2017;22:30452.

18. Nash D, Mostashari F, Fine A, Miller J, O'leary D, Murray K, et al. The outbreak of West Nile virus infection in the New York City area in 1999. N Engl J Med. 2001;344:1807-14.

19. ECDC. Aedes albopictus - current known distribution in Europe, April 2017. Stockholm, Sweden: European Centre for Disease Prevention and Control; 2018. https://ecdc.europa.eu/en/disease-vectors/surveillanceand-disease-data/mosquito-maps.

20. Kalluri S, Gilruth P, Rogers D, Szczur M. Surveillance of arthropod vectorborne infectious diseases using remote sensing techniques: a review. PLoS Pathog. 2007;3:e116.

21. Eisen RJ, Eisen L. Spatial modeling of human risk of exposure to vectorborne pathogens based on epidemiological versus arthropod vector data. J Med Entomol. 2008;45:181-92.

22. Esser HJ, Mögling R, Cleton NB, van der Jeugd H, Sprong H, Stroo A, et al. Risk factors associated with sustained circulation of six zoonotic arboviruses: a systematic review for selection of surveillance sites in nonendemic areas. Parasites Vectors. 2019;12:265.

23. Messina JP, Kraemer MU, Brady OJ, Pigott DM, Shearer FM, Weiss DJ, et al. Mapping global environmental suitability for Zika virus. Elife. 2016:5:e15272

24. Nsoesie EO, Kraemer MU, Golding N, Pigott DM, Brady OJ, Moyes CL, et al. Global distribution and environmental suitability for chikungunya virus, 1952 to 2015. Euro Surveill. 2016. https://doi.org/10.2807/1560-7917. es.2016.21.20.30234.

25. Racloz V, Presi P, Vounatsou P, Schwermer H, Casati S, Vanzetti T, et al, Use of mapping and statistical modelling for the prediction of bluetongue occurrence in Switzerland based on vector biology. Vet Ital. 2007:43:513-8.

26. Messina JP, Pigott DM, Golding N, Duda KA, Brownstein JS, Weiss DJ, et al. The global distribution of Crimean-Congo hemorrhagic fever. Trans R Soc Trop Med Hyg. 2015;109:503-13.

27. Anyamba A, Chretien JP, Small J, Tucker CJ, Formenty PB, Richardson JH, et al. Prediction of a Rift Valley fever outbreak. Proc Natl Acad Sci USA. 2009;106:955-9.

28. Pfeffer $\mathrm{M}$, Dobler $\mathrm{G}$. Emergence of zoonotic arboviruses by animal trade and migration. Parasites Vectors. 2010;3:35.

29. Jameson LJ, Morgan PJ, Medlock JM, Watola G, Vaux AGC. Importation of Hyalomma marginatum, vector of Crimean-Congo haemorrhagic fever virus, into the United Kingdom by migratory birds. Ticks Tick Borne Dis. 2012:3:95-9.

30. Rappole JH, Hubalek Z. Migratory birds and West Nile virus. J Appl Microbiol. 2003:94:47-58

31. RIVM. Zoonotic diseases report 2012. The Bilt, the Netherlands: National Institute for Public Health and the Environment; 2013. https://www.rivm. nl/bibliotheek/rapporten/092330002.pdf.

32. Butler CM, van Oldruitenborgh-Oosterbaan MMS, Stout TA, Jongejan $F$, Werners AH, Houwers DJ. Classification of ticks collected from horses in the Netherlands in 2008-2009 and identification of the (zoonotic) agents they contain. Pferdeheilkunde. 2016;32:329.

33. Misra UK, Kalita J. Overview: Japanese encephalitis. Prog Neurobiol. 2010:91:108-20.

34. Chevalier V, Pépin M, Plée L, Lancelot R. Rift Valley fever—a threat for Europe? Euro Surveill. 2010;15:19506.

35. Ergonul O, Whitehouse CA. Crimean-Congo hemorrhagic fever: a global perspective. Dordrecht: Springer Science \& Business Media; 2007.

36. Jaenson TG, Hjertqvist M, Bergström T, Lundkvist $\AA$. Why is tick-borne encephalitis increasing? A review of the key factors causing the increasing incidence of human TBE in Sweden. Parasites Vectors. 2012;5:184.
37. Kazarina A, Japiņa K, Keišs O, Salmane I, Bandere D, Capligina V, et al. Detection of tick-borne encephalitis virus in I. ricinus ticks collected from autumn migratory birds in Latvia. Ticks Tick Borne Dis. 2015;6:178-80

38. Braks MAH, Stroo CJ. The control of native mosquitoes in the Netherlands: possibilities and challenges. RIVM report 2016-0004. The Bilt, the Netherlands: RIVM; 2016. https://www.rivm.nl/bibliotheek/rappo rten/2016-0004.pdf.

39. Fros JJ, Geertsema C, Vogels CB, Roosjen PP, Failloux AB, Vlak JM, et al. West Nile virus: high transmission rate in north-western European mosquitoes indicates its epidemic potential and warrants increased surveillance. PLoS Negl Trop Dis. 2015;9:e0003956.

40. Vloet RPM, Vogels CBF, Koenraadt CJM, Pijlman GP, Eiden M, Gonzales $\mathrm{JL}$, et al. Transmission of Rift Valley fever virus from Europeanbreed lambs to Culex pipiens mosquitoes. PLoS Negl Trop Dis. 2017:11:e0006145.

41. Ibañez-Justicia A, Cianci D. Modelling the spatial distribution of the nuisance mosquito species Anopheles plumbeus (Diptera: Culicidae) in the Netherlands. Parasites Vectors. 2015;8:258.

42. Ibañez-Justicia A, Stroo A, Dik M, Beeuwkes J, Scholte EJ. National mosquito (Diptera: Culicidae) survey in The Netherlands 2010-2013. J Med Entomol. 2015;52:185-98.

43. Bird BH, Ksiazek TG, Nichol ST, MacLachlan NJ. Rift Valley fever virus. J Am Vet Med Assoc. 2009;234:883-93.

44. Lubisi BA, Ndouvhada PN, Neiffer D, Penrith ML, Sibanda DR, Bastos A. Seroprevalence of Rift valley fever in South African domestic and wild suids (1999-2016). Transbound Emerg Dis. 2020;67:811-21.

45. Bird BH, McElroy AK. Rift Valley fever virus: unanswered questions. Antivir Res. 2016;132:274-80.

46. Rostal MK, Liang JE, Zimmermann D, Bengis R, Paweska J, Karesh WB. Rift Valley fever: does wild life play a role? ILAR J. 2017:58:359-70.

47. Rizzoli A, Bolzoni L, Chadwick EA, Capelli G, Montarsi F, Grisenti M, et al. Understanding West Nile virus ecology in Europe: Culex pipiens host feeding preference in a hotspot of virus emergence. Parasites Vectors. 2015;8:213

48. Hubálek Z, Halouzka J. West Nile fever-a reemerging mosquito-borne viral disease in Europe. Emerg Infect Dis. 1999;5:643.

49. Rappole JH, Derrickson SR, Hubálek Z. Migratory birds and spread of West Nile virus in the western Hemisphere. Emerg Infect Dis. 2000;6:319.

50. Lim SM, Brault AC, van Amerongen G, Bosco-Lauth AM, Romo H, Sewbalaksing VD, et al. Susceptibility of carrion crows to experimental infection with lineage 1 and 2 West Nile viruses. Emerg Infect Dis. 2015;21:1357

51. Del Amo J, Llorente F, Figuerola J, Soriguer RC, Moreno AM, Cordioli P, et al. Experimental infection of house sparrows (Passer domesticus) with West Nile virus isolates of Euro-Mediterranean and North American origins. Vet Res. 2014;45:33.

52. Lim SM, Brault AC, van Amerongen $G$, Sewbalaksing VD, Osterhaus AD, Martina BE, et al. Susceptibility of European jackdaws (Corvus monedula) to experimental infection with lineage 1 and 2 West Nile viruses. J Gen Virol. 2014;95:1320-9.

53. Jiménez de Oya N, Camacho MC, Blázquez AB, Lima-Barbero JF, Saiz JC, Höfle U, et al. High susceptibility of magpie (Pica pica) to experimental infection with lineage 1 and 2 West Nile virus. PLoS Negl Trop Dis. 2018;12:e0006394.

54. Spedicato M, Carmine I, Bellacicco AL, Marruchella G, Marini V, Pisciella M, et al. Experimental infection of rock pigeons (Columba livia) with three West Nile virus lineage 1 strains isolated in Italy between 2009 and 2012. Epidemiol Infect. 2016;144:1301-11.

55. Kilpatrick AM, Meola MA, Moudy RM, Kramer LD. Temperature, viral genetics, and the transmission of West Nile virus by Culex pipiens mosquitoes. PLoS Pathog. 2008;4:e1000092.

56. Vogels CBF, Göertz GP, Pijlman GP, Koenraadt CJM. Vector competence of northern and southern European Culex pipiens pipiens mosquitoes for West Nile virus across a gradient of temperatures. Med Vet Entomol. 2017:34:358-64.

57. Bi P, Zhang Y, Parton KA. Weather variables and Japanese encephalitis in the metropolitan area of Jinan city, China. J Infect. 2007;55:551-6.

58. Marcantonio M, Rizzoli A, Metz M, Rosà R, Marini G, Chadwick E, et al. Identifying the environmental conditions favouring West Nile virus outbreaks in Europe. PLoS ONE. 2015;10:e0121158. 
59. Turell MJ, Rossi CA, Bailey CL. Effect of extrinsic incubation temperature on the ability of Aedes taeniorhynchus and Culex pipiens to transmit Rift Valley fever virus. Am J Trop Med Hyg. 1985;34:1211-8.

60. Estrada-Peña A, Martínez Avilés M, Muñoz Reoyo MJ. A population model to describe the distribution and seasonal dynamics of the tick Hyalomma marginatum in the Mediterranean Basin. Transbound Emerg Dis. 2011;58:213-23.

61. Lindström A, Jaenson TGT. Distribution of the common tick, Ixodes ricinus (Acari: Ixodidae), in different vegetation types in southern Sweden. J Med Entomol. 2003;40:375-8.

62. Uspensky I. Preliminary observations on specific adaptations of exophilic ixodid ticks to forests or open country habitats. Exp Appl Acarol. 2002:28:147-54.

63. Rizzoli A, Hauffe HC, Tagliapietra V, Neteler M, Rosà R. Forest structure and roe deer abundance predict tick-borne encephalitis risk in Italy. PLoS ONE. 2009;4:e4336.

64. Kiffner C, Zucchini W, Schomaker P, Vor T, Hagedorn P, Niedrig M, et al. Determinants of tick-borne encephalitis in counties of southern Germany, 2001-2008. Int J Health Geogr. 2010;9:42.

65. Zeimes CB, Olsson GE, Hjertqvist M, Vanwambeke SO. Shaping zoonosis risk: landscape ecology vs. landscape attractiveness for people, the case of tick-borne encephalitis in Sweden. Parasites Vectors. 2014;7:370.

66. Vanwambeke SO, Šumilo D, Bormane A, Lambin EF, Randolph SE. Landscape predictors of tick-borne encephalitis in Latvia: land cover, land use, and land ownership. Vector-Borne Zoonotic Dis. 2010;10:497-506.

67. Vescio FM, Busani L, Mughini-Gras L, Khoury C, Avellis L, Taseva E, et al. Environmental correlates of Crimean-Congo haemorrhagic fever incidence in Bulgaria. BMC Public Health. 2012;12:1.

68. Gilbert L. Louping ill virus in the UK: a review of the hosts, transmission and ecological consequences of control. Exp Appl Acarol. 2016:68:363-74.

69. Hofmeester TR, Sprong H, Jansen PA, Prins HHT, van Wieren SE. Deer presence rather than abundance determines the population density of the sheep tick, Ixodes ricinus, in Dutch forests. Parasites Vectors. 2017;10:433.

70. van Wieren SE, Hofmeester TR. The role of large herbivores in Ixodes ricinus and Borrelia burgdorferi s/ dynamics. In: Braks MAH, van Wieren SE, Takken W, Sprong H, editors. Ecology and prevention of Lyme borreliosis and vector-borne diseases. Wageningen: Wageningen Academic Publishers; 2016. p. 75-89.

71. Randolph SE. Transmission of tick-borne pathogens between cofeeding ticks: Milan Labuda's enduring paradigm. Ticks Tick Borne Dis. 2011:2:179-82

72. Jones LD, Gaunt M, Hails RS, Laurenson K, Hudson PJ, Reid H, et al. Transmission of louping ill virus between infected and uninfected ticks co-feeding on mountain hares. Med Vet Entomol. 1997;11:172-6.

73. Medlock JM, Hansford KM, Bormane A, Derdakova M, Estrada-Peña A, George JC, et al. Driving forces for changes in geographical distribution of Ixodes ricinus ticks in Europe. Parasites Vectors. 2013;6:1.

74. Estrada-Peña A, Bouattour A, Camicas JL, Walker AR. Ticks of domestic animals in the Mediterranean region: a guide to identification of species. Zaragoza: University of Zaragoza; 2004

75. Estrada-Peña A, Sánchez N, Estrada-Sánchez A. An assessment of the distribution and spread of the tick Hyalomma marginatum in the western Palearctic under different climate scenarios. Vector Borne Zoonotic Dis. 2012;12:758-68.

76. Estrada-Peña A, Venzal JM. Climate niches of tick species in the Mediterranean region: modeling of occurrence data, distributional constraints, and impact of climate change. J Med Entomol. 2007;44:1130-8.

77. Williams HW, Cross DE, Crump HL, Drost CJ, Thomas CJ. Climate suitability for European ticks: assessing species distribution models against null models and projection under AR5 climate. Parasites Vectors. 2015;8:440.

78. Sluiter R. Interpolation methods for the climate atlas. Technical report; TR-335. The Bilt, the Netherlands: KNMl; 2012. http://bibliotheek.knmi.nl/ knmipubTR/TR335.pdf.

79. Hazeu GW, Schuiling C, Dorland GJ, Roerink GJ, Naeff HSD, Smidt RA. Landelijk Grondgebruiksbestand Nederland versie 7 (LGN7): manufacture, accuracy, and use. Wageningen: Alterra Wageningen UR; 2014. http:// content.alterra.wur.nl/Webdocs/PDFFiles/Alterrarapporten/AlterraRap port2548.pdf

80. NDFF. NDFF Verspreidingsatlas. 2018. https://www.verspreidingsatlas.nl/.
81. SOVON, Dutch centre for field ornithology. Bird atlas Netherlands: breeding and wintering birds and 40 years of change. Utrecht/Antwerpen: Kosmos Uitgevers; 2018.

82. Ostfeld RS, Glass GE, Keesing F. Spatial epidemiology: an emerging (or re-emerging) discipline. Trends Ecol Evol. 2005;20:328-36.

83. RIVM. Spread of tick-borne encephalitis virus in the Netherlands. The Bilt, the Netherlands: RIVM; 2020. https://www.rivm.nl/en/news/spread-oftick-borne-encephalitis-virus-in-netherlands. Accessed 6 July 2020.

84. Lim SM, Geervliet M, Verhagen JH, Müskens G, Majoor FA, Osterhaus $A D$, et al. Serologic evidence of West Nile virus and Usutu virus infections in Eurasian coots in the Netherlands. Zoonoses Public Health. 2018:65:96-102.

85. Miller RH, Masuoka P, Klein TA, Kim H-C, Somer T, Grieco J. Ecological niche modeling to estimate the distribution of Japanese encephalitis virus in Asia. PLoS Negl Trop Dis. 2012;6:e1678.

86. Ziegler U, Lühken R, Keller M, Cadar D, van der Grinten E, Michel F, et al. West Nile virus epizootic in Germany, 2018. Antivir Res. 2019;162:39-43.

87. Paz S. Climate change impacts on West Nile virus transmission in a global context. Philos Trans R Soc B. 2015;370:20130561.

88. Semenza JC, Tran A, Espinosa L, Sudre B, Domanovic D, Paz S. Climate change projections of West Nile virus infections in Europe: implications for blood safety practices. Environ Health. 2016;15:S28.

89. Laurenson MK, Norman RA, Gilbert L, Reid HW, Hudson PJ. Identifying disease reservoirs in complex systems: mountain hares as reservoirs of ticks and louping-ill virus, pathogens of red grouse. J Anim Ecol. 2003;72:177-85.

90. McGuire K, Holmes EC, Gao GF, Reid HW, Gould EA. Tracing the origins of louping ill virus by molecular phylogenetic analysis. J Gen Virol. 1998;79:981-8.

91. van den Hurk AF, Ritchie SA, Mackenzie JS. Ecology and geographical expansion of Japanese encephalitis virus. Annu Rev Entomol. 2009;54:17-35

92. EFSA Panel on Animal Health and Welfare (AHAW). Scientific opinion on rift valley fever. EFSA J. 2013;11:3180.

93. Ogden NH, St-Onge L, Barker IK, Brazeau S, Bigras-Poulin M, Charron DF, et al. Risk maps for range expansion of the Lyme disease vector, Ixodes scapularis, in Canada now and with climate change. Int J Health Geogr. 2008;7:24.

94. Guerra M, Walker E, Jones C, Paskewitz S, Cortinas MR, Stancil A, et al. Predicting the risk of Lyme disease: habitat suitability for Ixodes scapularis in the north central United States. Emerg Infect Dis. 2002;8:289-97.

95. Brooker S. Spatial epidemiology of human schistosomiasis in Africa: risk models, transmission dynamics and control. Trans R Soc Trop Med Hyg. 2007;101:1-8.

96. de la Torre A, Bosch J, Iglesias I, Muñoz MJ, Mur L, Martínez-López B, et al. Assessing the risk of African swine fever introduction into the European Union by wild boar. Transbound Emerg Dis. 2015;62:272-9.

\section{Publisher's Note}

Springer Nature remains neutral with regard to jurisdictional claims in published maps and institutional affiliations.

Ready to submit your research? Choose BMC and benefit from:

- fast, convenient online submission

- thorough peer review by experienced researchers in your field

- rapid publication on acceptance

- support for research data, including large and complex data types

- gold Open Access which fosters wider collaboration and increased citations

- maximum visibility for your research: over 100M website views per year

At BMC, research is always in progress.

Learn more biomedcentral.com/submissions 